\title{
To study the maternal and fetal outcome in obese pregnant mothers compared with non-obese pregnant mothers in an urban population
}

\author{
Authors: Rajeev Upreti ${ }^{\mathrm{A}}$ and Ram Shankar Mishra ${ }^{\mathrm{B}}$
}

\section{Introduction}

The objective of this study was to assess the maternal and fetal outcome in obese mothers (body mass index (BMI) $>27.5 \mathrm{~kg} / \mathrm{m}^{2}$ ) compared with non-obese mothers (BMI $<27.5 \mathrm{~kg} / \mathrm{m}^{2}$ ) and to observe the persistence of abnormalities in mother and newborn for 6 weeks post-partum.

\section{Methods}

This was a prospective case-control study comprising pregnant women attending the outdoor or indoor services of the Department of Obstetrics and Gynaecology at Max Hospital, National Capital Region, and fulfilling the inclusion criteria. This study was conducted from October 2013 to December 2014. The sample size was calculated by using n-Master (2.0) software and 200 women were enrolled. Data were analysed by using the chisquare test and Pearson's correlation coefficient.

\section{Results and discussion}

Higher incidence of the following conditions was observed in the obese group than in the non-obese group: pregnancy-induced hypertension (PIH; $10.4 \%, p=0.041$ ), PIH as a statistically significant contributing factor for surgical interference during delivery (24.1\%, $\mathrm{p}=0.005$ ), non-progression of labour (NPOL; $14.3 \%, p=0.542$ ), fetal distress $(16.9 \%, p=0.346)$, preterm delivery $(20.8 \%, p=0.016)$, postpartum diabetes mellitus (DM; $9.1 \%, p=0.006)$ and hypertension (3.9\%). More neonatal intensive care unit (NICU) admissions were seen in the obese group $(26.0 \%, p=0.614)$ and more infants had feeding problems at 6 weeks post-partum in the obese group $(2.6 \%, p=0.639)$.

\section{Conclusion}

Obesity is a leading cause of both maternal and fetal complications. BMI screening and counselling should be done pre-conception for all women to make them aware of possible

Authors: ${ }^{A}$ George Eliot Hospital, Nuneaton, UK; ${ }^{B}$ Max Hospital, Saket, India obesity-related complications during and after pregnancy. It is advised that BMI cut-off is kept at $<27.5 \mathrm{~kg} / \mathrm{m}^{2}$ for women in pregnancy (and the general population), as suggested by the World Health Organization (WHO) Regional Office (International Obesity Task Force). ${ }^{1}$ Comorbid screening should be early and more intense in pregnant obese women.

\section{Reference}

1 WHO Expert Consultation. Appropriate body-mass index for Asian populations and its implications for policy and intervention strategies. Lancet 2004:363:157-63. 